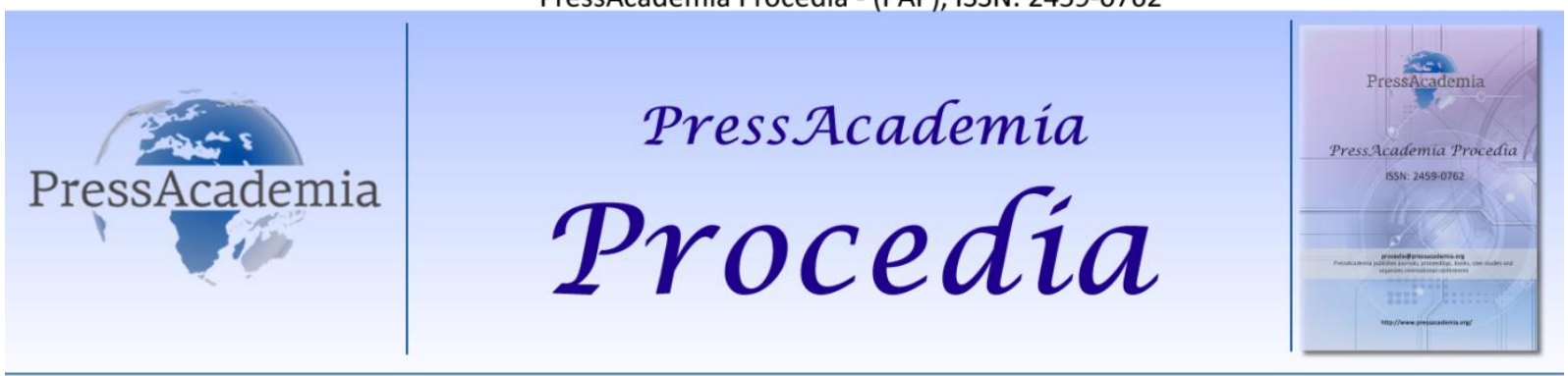

2nd World Conference on Technology, Innovation and Entrepreneurship

May 12-14, 2017, Istanbul, Turkey. Edited by Sefer Şener

\title{
DECISION MAKING TECHNIQUES FOR ELECTRONIC COMMUNICATION: AN EXAMPLE FOR TURKEY
}

\section{DOI: 10.17261/Pressacademia.2017.585}

PAP-WCTIE-V.5-2017(23)-p.162-168

Semra Erpolat Tasabat ${ }^{1}$, Olgun Aydin ${ }^{2}$

${ }^{1}$ Mimar Sinan Fine Art University. semra.erpolat@msgsu.edu.tr

${ }^{2}$ Mimar Sinan Fine Art University. olgun.aydin@ogr.msgsu.edu.tr

\begin{abstract}
Communication is the way for people exchanging information with each other by using various tools. Electronic communication or Ecommunication is the process of sending, receiving and processing information or messages electronically. Electronic communication that is closely related to the development levels of countries, has made considerable progress especially in terms technology, innovation and entrepreneur. In this study, it is investigated whether electronic communication in Turkey is used effectively using the data published by Information and Communication Technologies Authority. For this purpose, different decision making techniques in data mining have been used. Obtained results are discussed.
\end{abstract}

Keywords: Multi criteria decision making, electre, topsis, electronic communication, data mining.

\section{INTRODUCTION}

Decision making, an inseparable part of life, is the process of choosing one of the available alternatives in order to achieve the specified goals and objectives. Life and working conditions that are rapidly changing and evolving at the same time are increasingly challenging people, institutions or businesses to consistently make "good" and "successful" decisions. Increasing the number of alternatives and criterions in complex decision problems, the contradiction of the criteria, made the selection process very difficult. Undoubtedly, the only way for institutions to gain superiority to their competitors in increasingly competitive conditions is to make quick and correct decisions.

Multi-Criteria Decision Making (MCDM), which is increasingly receiving more attention in recent years, incorporates approaches and methods that try to achieve a possible "best fit" solution that meets more than one criterion that conflicts with a decision situation.

One of the sectors where it is important to make the right decisions is electronic communications. With increasing technological progress and innovations, countries with an increasingly prevalent electronic communication are important elements to shape the future.

In the study, ELECTRE III and TOPSIS were taken up from MCDM methods to evaluate the activities of 81 provinces of Turkey in electronic communication sector. In the application of the mentioned methods, the weights of the determined criteria are determined according to the variable importance scores obtained in the neural network result.

\section{LITERATURE REVIEW}

From the literature view, it seems that in recent years, the efforts of electronic communication decision-making techniques have started to increase.

Feldman et. al have developed recommendations on when and how to use electronic communication to strengthen decision-making in their work, and explain various decision contexts (Feldman, et. al, 1996). Büyüközkan et. al, have developed a multi criteria group decision making Approach in smart phone selection using intuitive fuzzy TOPSIS (Büyüközkan, 2016). 
Ertugrul et. al. have used the concept of fuzzy logic based on individual knowledge and experience in selecting the mobile line that provides the most economical, best and most appropriate solutions for the business needs in their work (Ertugrul et. al, 2014).

Petrovic et. al have offered a decision support tool for step-by-step benchmarking in their work. In a benchmarking exercise, a method is proposed for selecting a preferred development pathway comprising a series of intermediate test sequences(Petrovic et. al, 2014). Kaya et. al. have proposed an e-banking website quality assessment method based on an integrated fuzzy AHP-ELECTRE approach.

The fuzzy set theory has developed to deal with the problems arising from the uncertainty, uncertainty and the nature of human judgment (Kaya et. al ,2011). Chen et. al. investigated the relationship between the player and the struggling player in wireless communication (Chen et. al., 2010).

Asghari et. al. explored five different business models in the field of mobile payments. The MCDM has compared the evaluation method with its applications. Since one of the most effective parameters for selecting a suitable business model is the structure of banks / operators of each country, the proposed business model has been localized based on the framework of operators in Iranian banks (Asghari et. al, 201)

\subsection{Multi-Criteria Decision Making Methods}

It is possible for businesses to adapt to rapidly changing environmental conditions and make effective decisions in parallel with this change by using scientific methods that can evaluate a large number of qualitative and quantitative factors together in the decision-making process (Taha, 1997).

There are different methods used in the literature for the solution of MCDM problems, none of which provide a complete superiority over others (Dağdeviren, 2007).The most widely used methods of MCDM are ELECTRE, TOPSIS, Promethee, Vikor, Oreste, Mappac and Weighted Sum Approach (WSA). These methods have always been developed according to historical order in order to overcome the theoretical deficiencies of the previous method.

Because of being the most used methods in the literature, the activities in Turkey in the field of electronic communication in Turkey have been investigated by means of ELECTRE and TOPSIS methods in line with the criteria determined by Information and Communication Technologies Authortity (ICTA). In the following section methods are briefly mentioned.

\subsubsection{ELECTRE Methods}

ELECTRE (Elimination et Choix Traduisant La Realite - Elimination and Choice Translating Reality) is one of the MCDM methods originally developed by Benayoun, Roy et al. In 1966 (Roy 1968, 1991). The method incorporating a systematic analysis of the relationships between all possible pairs of different alternatives is based on the scores on each set of common criteria in each alternative. In the literature, there are several variants of the ELECTRE method in the form of ELECTRE I, II, III, IV, IS, TRI. All methods are based on the same fundamental concepts, but are both operationally and according to the type of decision problem. Specifically, ELECTRE I is designed for selection problems, ELECTRE TRI for assignment problems and ELECTRE II, III and IV for ranking problems. ELECTRE II is an old version; ELECTRE III is used when it is possible to quantify the relative importance of the criterion and when the quantification is not possible (Hokkanen, J. and P. Salminen 1997). In this study, ELECTRE III method based on pseudo-criteria and fuzzy binary outranking relations is used.

It is possible to summarize the functioning of the method in the form of the decision matrix formation, the formation of the standard decision matrix, the formation of the weighted standard decision matrix, the determination of compliance and nonconformity sets, the formation of compliance and nonconformity matrices, the formation of matrices of superiority and nonconformity superiority matrices.

\subsubsection{TOPSIS Method}

TOPSIS (Technique for Order Preference by Similarity to Ideal Solution) was developed by Yoon and Hwang as an alternative to the ELECTRE method in 1980 (Hwang, 1981).

The TOPSIS method consists of the generation of the decision matrix, the creation of the standard decision matrix, the creation of the weighted standard decision matrix, the creation of ideal and negative ideal solutions, the calculation of the separation measures, and the calculation of the ideal solution relative localization (Chen, 2000).

\subsection{Variable Importance and Feature Selection}

Data mining problems may involve hundreds, or even thousands, of fields that can potentially be used as predictors. As a result, a great deal of time and effort may be spent examining which fields or variables to include in the model. To narrow down the choices, the Feature Selection algorithm can be used to identify the fields that are most important for a given 
analysis (Clementine Users Guide)

Typically, it can be considered to focus on the variables that give the most importance to modeling efforts and to at least ignore or ignore those that are insignificant. Variable precaution assists in making this variable by specifying the relative importance of each variable in model prediction. Since the values are relative, the sum of the values for all variables on the display is "1.0". Variable importance does not relate to model accuracy. It just relates to the importance of each variable in making a prediction, not whether or not the prediction is accurate. On the other hand "feature selection" ranks each predictor based on the strength of its relationship to the specified target, independent of other predictors. Thus feature selection will be more conservative in screening predictors. But in modeling, interactions and correlations are also taken into consideration (Clementine Users Guide). The importance levels obtained as a result of variable importance or feature selection can be used for analysis by considering them as variable weights. The weight determination process, which has an important place in the MCDM methods, is one of the most important steps of the decision analysis. Different techniques have been used in the literature to weight variables. In this study we used variable importance weights obtained from neural network analysis to weight the criteria.

\subsection{Electronic Communication}

Communication is needed for decision making, co-ordination, control, and planning. Communication, which is an integral part of our life, has become increasingly easier, faster and at the same time more understandable with developing technology. Communication using electronic media known as electronic communication. Worldwide communication has been facilitated by the electronic transmission of data which connects individuals, regardless of geographic location, almost instantly (http://www.meammarketing.com/advantages-and-disadvantages-of-electronic- communication/). One of the important research topics of today is how to manage the electronic communication, which is a demonstration of the level of development of the countries, better and more efficiently.

\section{DATA AND METHODOLOGY}

In the study, the variables used in the electronic communication sector to investigate which of the 81 provinces of Turkey are active in the electronic communication sector are discussed by Information Technologies and the publication of the year 2016 by the communication institution. The following table contains these variables and explanations.

Table 1: Explanations

\begin{tabular}{|l|l|l|}
\hline $\begin{array}{l}\text { Variable } \\
\text { Code }\end{array}$ & Variable Name & Explanations \\
\hline V1 & Population & $\begin{array}{l}\text { Data shows population statistics of Turkish Statistical } \\
\text { Agency. }\end{array}$ \\
\hline V2 & Number of Fixed Telephony Access Lines & $\begin{array}{l}\text { It includes number of active fixed analogue telephony } \\
\text { access lines, voice channels equivalent of ISDN lines } \\
\text { fixed wireless subscriptions, number of payphones } \\
\text { and number of VolP subscriptions. }\end{array}$ \\
\hline V3 & Santral Capacity of Fixed Telephony & $\begin{array}{l}\text { It shows total capacity of fixed telephone lines that } \\
\text { can be handled. It shows number of xDSL broadband } \\
\text { internet subscriptions. }\end{array}$ \\
\hline V4 & Number of Payphones & It shows number of active payphones. \\
\hline V5 & Number of Mobile Telephony Subscriptions - Total & $\begin{array}{l}\text { It shows total number of mobile telephony } \\
\text { subscriptions. }\end{array}$ \\
\hline V6 & Number of Mobile Telephony Subscriptions - 2G & $\begin{array}{l}\text { It shows total number of 2G mobile telephony } \\
\text { subscriptions. }\end{array}$ \\
\hline V7 & Number of Mobile Telephony Subscriptions - 3G* & $\begin{array}{l}\text { It shows total number of 3G mobile telephony } \\
\text { subscriptions. }\end{array}$ \\
\hline V8 & Number of Broadband Subscriptions - Total & $\begin{array}{l}\text { It shows total number of broadband internet } \\
\text { subscriptions. }\end{array}$ \\
\hline V9 & Number of Fixed Broadband Subscriptions - Total & $\begin{array}{l}\text { It shows total number of fixed broadband internet } \\
\text { subscriptions. }\end{array}$ \\
\hline V10 & Fiber & $\begin{array}{l}\text { It shows number of fiber broadband internet } \\
\text { subscriptions. }\end{array}$ \\
\hline V11 & xDSL & $\begin{array}{l}\text { It shows number of xDSL broadband internet } \\
\text { subscriptions. }\end{array}$ \\
\hline V12 & Cable & It shows number of Cable TV broadband internet \\
\hline
\end{tabular}




\begin{tabular}{|c|c|c|}
\hline & & subscriptions. \\
\hline V13 & Other & $\begin{array}{l}\text { It shows number of broadband internet subscriptions } \\
\text { via other means (Frame Relay, Metrı Ethernet, ATM, } \\
\text { BPL). }\end{array}$ \\
\hline V14 & Number of Mobile Broadband Subscriptions ** & $\begin{array}{l}\text { It shows number of mobile broadband internet } \\
\text { subscriptions via } 3 G \text { or other appropriate mobile } \\
\text { networks. }\end{array}$ \\
\hline V15 & Mobile Broadband Dedicated & $\begin{array}{l}\text { It shows number of mobile broadband internet } \\
\text { subscriptions via dedicated data cards. }\end{array}$ \\
\hline V16 & Standard Mobile Broadband & $\begin{array}{l}\text { It shows number of mobile broadband internet } \\
\text { subscriptions via mobile phones. }\end{array}$ \\
\hline V17 & Number of Cable TV Subscriptions & It shows number of cable TV subscriptions. \\
\hline V18 & The length of fiber*** & $\begin{array}{l}\text { It shows length of fiber rolled out for transmission and } \\
\text { access. }\end{array}$ \\
\hline
\end{tabular}

* 3G Mobile telephone services have been provided since 2009.

** Mobile broadband ratio given here is updated. Currently, it includes the subscribers who have used packages less than one month period, who have used packages longer than one month period and who have accessed internet without any packages. Before, it was just consisted of the subscribers who had packages longer than one month period.

*** The length of fiber data about 2011, 2012, 2013, 2014 and 2015 include data obtained by alternative infrastructure operators.

In the study, Cities were taken as an alternative and the variables determined by ICTA as criteria. Variables V5, V9, V14 are not included in the analyzes since the sum of V 5 variables V 6 and V7, the sum of V9 variables V10, V11, V12 and V13, is the sum of V14 variables V15 and V16. Thus, a total of 15 criteria were used to measure the activities of the illicit people in electronic communication. The application part of the study consists of three phases; data analysis, variable weighting and efficiency study. The data mining program, called Clementine, was used in the data mining to perform data analysis and weighting. The SANNA plug-in of Excel is used to perform the event analysis.

In the data analysis phase, first, the existence of nudge, outliers and null values were investigated to check whether there were erroneous data entries. Following the necessary regulations, the distributions of the variables were examined and the normal test was performed. A logarithmic transformation is applied to the variables to provide a normality assumption.

A neural network was used to determine the variable weights of the variables that were organized at the end of the data analysis phase during the variable weighting phase. The purpose of the neural network applied here is only to determine the weights. In the study, "population (V1)" is considered as variable target and other variables as input. Since all of the target and input variables are continuous, the variable importance analysis is based on the statistical based on the correlation coefficient. Figure 1 shows a screenshot of the data analysis and variable weighting steps.

\section{Figure 1: Clementine Screen Shot}

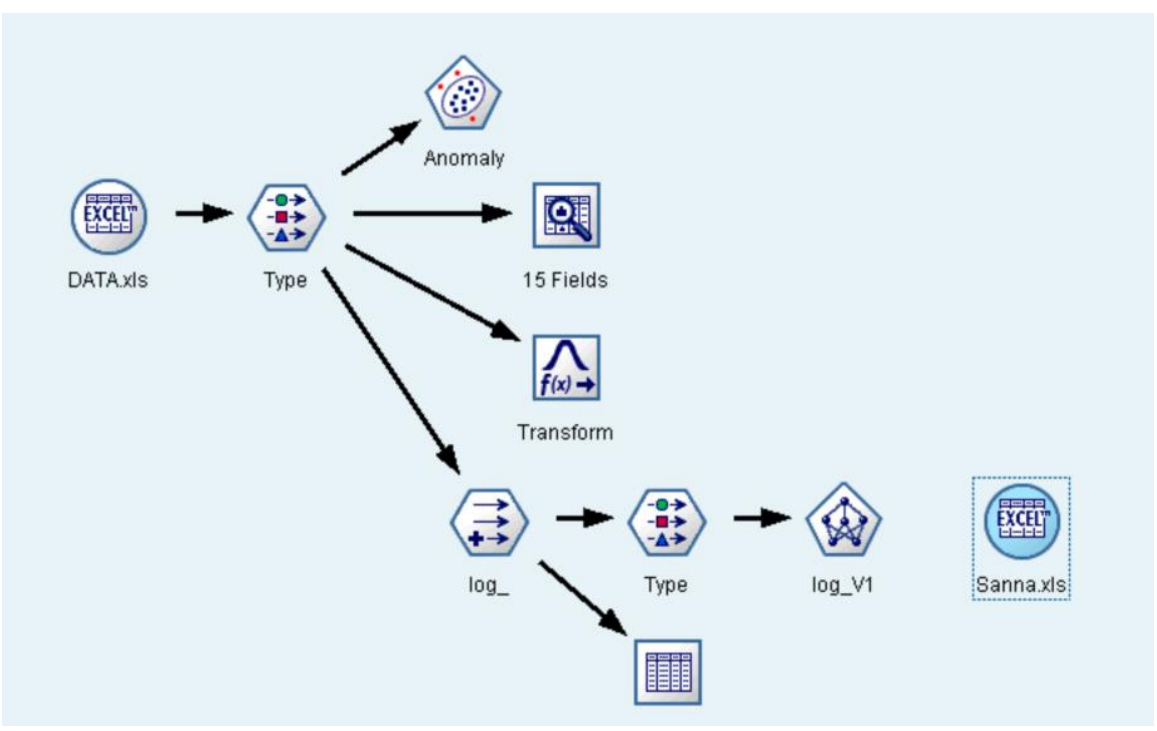


In the stage of efficiency analysis, the efficiency of 81 provinces was determined by means of ELECTRE III and TOPSIS methods to use the weights obtained during variable weighting. In Figure 2, there is a section from the screenshot of the data part of the program where the analysis is performed.

Figure 2: Sanna Plug-in Screen Shot

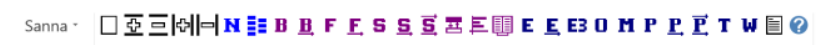

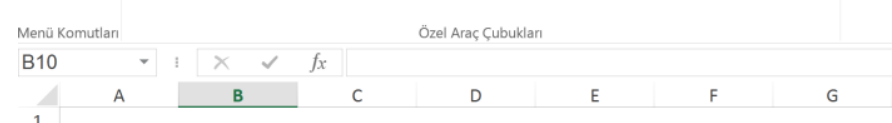

\section{Multicriteria evaluation of alternatives}

input and edit of data

on 3.4.2017

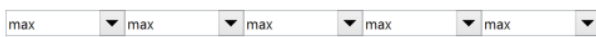

\begin{tabular}{|c|c|c|c|c|c|}
\hline & 1.Criterion & 2.Criterion & 3.Criterion & 4.Criterion & 5.Criterion \\
\hline 1.Alternative & 5,282030328 & 5,656015745 & 3,105510185 & 5,62500772 & 6,207036498 \\
\hline 2.Alte & 4,5406613 & 4,740741545 & 2,526339277 & 4,939034769 & 5,663088147 \\
\hline 3.Alternative & 4,88953629 & 5,223127166 & 2,840106094 & 5,123776531 & 5,717171027 \\
\hline 4.Alternative & 4,171442913 & 4,615802808 & 2,649334859 & 4,902389122 & 5,573240712 \\
\hline 5.Alternative & 4,673966841 & 4,950442748 & 2,770852012 & 4,888808288 & 5,459404551 \\
\hline 6.Alternative & 6,040691034 & 6,31008934 & 3,794139356 & 6,138497534 & 6,589014024 \\
\hline 7.Alternative & 5,492459456 & 5,874419191 & 3,605412798 & 5,703016094 & 6,23687595 \\
\hline 8.Alterna & 4,440108285 & 4,81130684 & 2,28780173 & 4,546974276 & 5,106907894 \\
\hline 9.Alte & 5,236752465 & 5,54645629 & 3,06669855 & 5,342738417 & 5,813946416 \\
\hline 10.Alter & 5,365255834 & 5,677253717 & 3,178113252 & 5,394316818 & 5,889955174 \\
\hline 11.Alternative & 4,613859621 & 4,845370939 & 2,836324116 & 4,719952447 & 5,099096817 \\
\hline
\end{tabular}

\section{FINDINGS AND DISCUSSIONS}

The significance levels of the variables studied in the study of Turkey's effectiveness in the electronic communication sector are determined by means of the neural network model which gives the best estimation level with the Estimated Accuracy rate $99,539 \%$. In the model in which the multiple method is used, there are two hidden layers containing 19 and 10 neurons, respectively. The variable importance values reached as a result of Neurol network analysis are as shown in Figure 3.

Figure 3: Results of Variable Importance

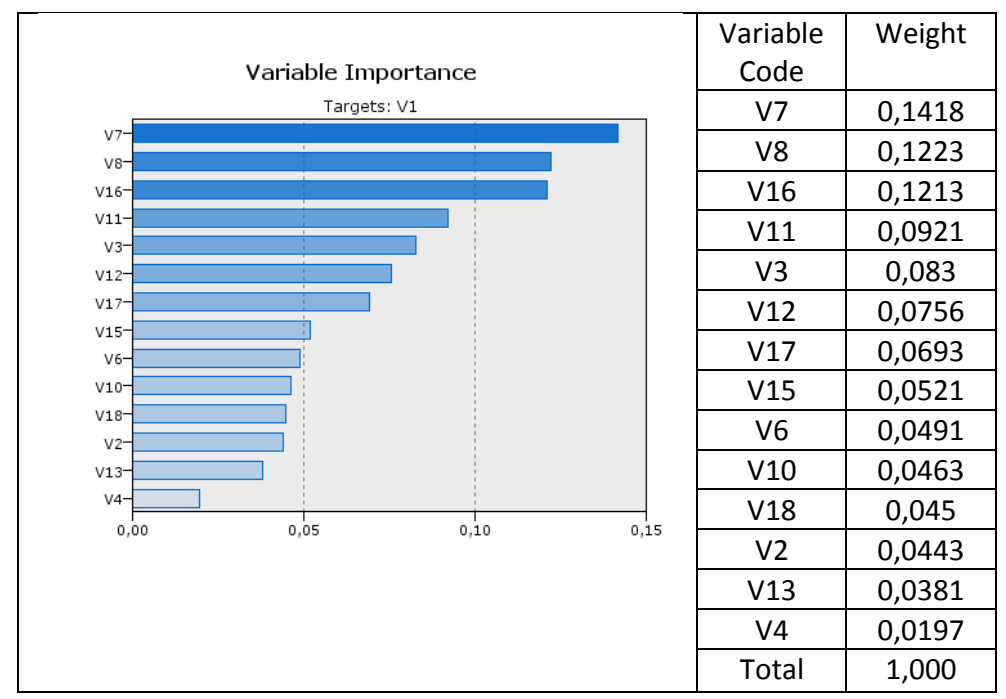

According to the results of the analysis, the three most important criteria in electronic communication were determined as Number of Mobile Telephony Subscriptions - 3G (V7), Number of Broadband Subscriptions - Total (V8) and Standard Mobile Broadband (V16). 
As a result of considering the variable importance levels as criterial weights, the results of the applied methods of ELECTRE III and TOPSIS are as follows respectively.

Table 2: Order of Alternatives According to ELECTRE III and TOPSIS Methods

\begin{tabular}{|c|c|c|c|c|c|c|c|c|}
\hline RANK & ELECTRE III & TOPSIS & $\begin{array}{c}\text { RAN } \\
\mathrm{K}\end{array}$ & ELECTRE III & TOPSIS & RANK & ELECTRE III & TOPSIS \\
\hline 1 & ISTANBUL & ISTANBUL & 28 & MALATYA & ŞANLIURFA & 55 & KiLis & RizE \\
\hline 2 & ANKARA & ANKARA & 29 & KAHRAMANMARAŞ & TRABZON & 56 & NEVŞEHIR & YOZGAT \\
\hline 3 & IZMiR & IZMiR & 30 & AFYONKARAHISAR & SAKARYA & 57 & NiĞDE & AĞRI \\
\hline 4 & BURSA & BURSA & 31 & SIVAS & KAHRAMANMARAŞ & 58 & AĞRI & NEVŞEHIR \\
\hline 5 & ANTALYA & ANTALYA & 32 & KÜTAHYA & MALATYA & 59 & KIRIKKALE & ŞIRNAK \\
\hline 6 & ADANA & ADANA & 33 & ELAZIĞ & AFYONKARAHISAR & 60 & YALOVA & NiĞDE \\
\hline 7 & KONYA & KONYA & 34 & ÇANAKKALE & VAN & 61 & BURDUR & KARABÜK \\
\hline 8 & KOCAELI & KOCAELI & 35 & ÇORUM & ORDU & 62 & BATMAN & KIRIKKALE \\
\hline 9 & GAZIANTEP & GAZIANTEP & 36 & IĞDIR & SIVAS & 63 & KARAMAN & BURDUR \\
\hline 10 & iÇEL & iÇEL & 37 & ORDU & ÇANAKKALE & 64 & KARS & BILECIK \\
\hline 11 & MANISA & MANISA & 38 & VAN & DÜZCE & 65 & BILECIK & SiliRT \\
\hline 12 & KAYSERI & DENIZLi & 39 & MARDIN & KÜTAHYA & 66 & KIRŞEHIR & KARS \\
\hline 13 & SAMSUN & KAYSERI & 40 & GIRESUN & MARDIN & 67 & SINOP & KIRŞEHIR \\
\hline 14 & DENIZLi & ESKIŞEHIR & 41 & ISPARTA & ELAZIĞ & 68 & BiTLIS & BARTIN \\
\hline 15 & BALIKESIR & TEKIRDAĞ & 42 & AMASYA & ADIYAMAN & 69 & SiiRT & BiTLIS \\
\hline 16 & ESKIŞEHIR & BALIKESIR & 43 & KASTAMONU & ÇORUM & 70 & ŞIRNAK & ARTVIN \\
\hline 17 & TEKIRDAĞ & SAMSUN & 44 & DÜZCE & TOKAT & 71 & BINGÖL & BINGÖL \\
\hline 18 & ERZURUM & ZONGULDAK & 45 & RiZE & AMASYA & 72 & ARTVIN & SINOP \\
\hline 19 & ZONGULDAK & ERZURUM & 46 & OSMANIYE & KIRKLARELI & 73 & ÇANKIRI & MUŞ \\
\hline 20 & EDIRNE & EDIRNE & 47 & YOZGAT & AKSARAY & 74 & MUŞ & ÇANKIRI \\
\hline 21 & MUĞLA & YALOVA & 48 & UŞAK & ISPARTA & 75 & GÜMÜŞHANE & HAKKARI \\
\hline 22 & AYDIN & ERZINCAN & 49 & BOLU & GIRESUN & 76 & HAKKARi & GÜMÜŞHANE \\
\hline 23 & SAKARYA & KARAMAN & 50 & ERZINCAN & KASTAMONU & 77 & ARDAHAN & IĞDIR \\
\hline 24 & HATAY & MUĞLA & 51 & BAYBURT & OSMANIYE & 78 & BARTIN & KILIS \\
\hline 25 & TRABZON & HATAY & 52 & TOKAT & BOLU & 79 & KARABÜK & ARDAHAN \\
\hline 26 & DIYARBAKIR & DIYARBAKIR & 53 & KIRKLARELI & BATMAN & 80 & AKSARAY & BAYBURT \\
\hline 27 & ŞANLIURFA & AYDIN & 54 & ADIYAMAN & UŞAK & 81 & TUNCELI & TUNCELI \\
\hline
\end{tabular}

According to Table 2 ELECTRE III and TOPSIS methods, it is seen that the first 11 provinces which are most effective in electronic communication sector are the same. These are Istanbul, Ankara, Izmir, Bursa, Antalya, Adana, Konya, Kocaeli, Gaziantep, içel and Manisa respectively. In both methods, it is seen that the province with the lowest value in the order of activity is Tunceli.

\section{CONCLUSION}

In the field of electronic communication, the data in Turkey provided by ICTA were utilized for ordering cities according to their activities in electronic communication.

In the study, the ELECTRE III and TOPSIS methods used in ordering from the MCDM techniques were utilized. In terms of weighting the criteria, a different approach has been taken to use the variable importance values obtained as a result of neural network analysis.

According to the results obtained, the criteria of $3 G$ (V7), Standard Mobile Broadband (V13) and Number of Broadband Subscriptions - Total (V7) In the order of the results of the ELECTRE III and TOPSIS analyzes, it is seen that the first five and the last two orders are the same for both methods. According to this, the most effective illicit items in electronic communication were respectively Istanbul, Ankara, Izmir, Bursa, Antalya and the least efficient ones were Bayburt and Kilis.

\section{REFERENCES}

Chen, C. T. (2000). Extensions of the TOPSIS for Group Decision-Making under Fuzzy Environment. Fuzzy Sets and Systems, Vol: 114.

Clementine User Guide, https://web.kku.ac.th/wichuda/DMining/ClementineUsersGuide_11.1.pdf

Hokkanen, J. and P. Salminen (1997), ELECTRE III and IV decision aids in an environmental problem, Journal of Multi-criteria Decision Analysis, 6, 215-226. 
Hwang, C. L. ve Yoon, K., Multiple Attribute Decision Making: A State of the Art Survey, Springer-Verlag, New York 1981.

Roy, B. (1968), Classement et choix en présence de critères multiples (la méthode ELECTRE), RIRO, 8, 57-75.

Roy, B. (1991), The outranking approach and the foundation of ELECTRE methods, Theory and Decision, 31, 49-73.

Roy, B., M. Présent and D. Silhol (1986), A programming method for determining which Paris Metro stations should be renovated, European Journal of Operational Research, 24, 318- 334.

http://www.meammarketing.com/advantages-and-disadvantages-of-electronic-communication/

Feldman, M. S.; Sarbaugh-Thompson, M. Information Infrastructure and Policy, v5 n1 p1-14 Jul 1996

Büyüközkan, Gülçin, and Sezin Güleryüz. "Multi Criteria Group Decision Making Approach for Smart Phone Selection Using Intuitionistic Fuzzy TOPSIS." International Journal of Computational Intelligence Systems 9.4 (2016): 709-725.

Ertugrul, Irfan, and Tayfun Oztas. "Business mobile-line selection in Turkey by using fuzzy TOPSIS, one of the multi-criteria decision methods." Procedia Computer Science 31 (2014): 40-47.

Petrović, Marijana, et al. "An ELECTRE-based decision aid tool for stepwise benchmarking: An application over EU Digital Agenda targets." Decision Support Systems 59 (2014): 230-241.

Kaya, Tolga, and Cengiz Kahraman. "A fuzzy approach to e-banking website quality assessment based on an integrated AHP-ELECTRE method." Technological and Economic Development of Economy 17.2 (2011): 313-334.

CHEN, Ya-ding, Shao-qian LI, and Yu-fan CHENG. "Effectiveness Evaluation of Integrated Anti-Jamming for Wireless Communication System." Journal of University of Electronic Science and Technology of China 39.3 (2010): 196-199.

Asghari, Fatemeh, et al. "A fuzzy ELECTRE approach for evaluating mobile payment business models." Management of e-Commerce and eGovernment (ICMeCG), 2010 Fourth International Conference on. IEEE, 2010. 